\title{
Increasing gender differences in the prevalence and chronification of orofacial pain in the population
}

Birgitta Häggman-Henrikson ${ }^{a, b}$, Per Liv $^{c}$, Aurelia llgunas ${ }^{a, b}$, Corine M. Visscher ${ }^{d}$, Frank Lobbezoo ${ }^{d}$, Justin Durham ${ }^{e}$, Anna Lövgren ${ }^{\mathrm{b}, \star}$

\begin{abstract}
Although a fluctuating pattern of orofacial pain across the life span has been proposed, data on its natural course are lacking. The longitudinal course of orofacial pain in the general population was evaluated using data from routine dental check-ups at all Public Dental Health services in Västerbotten, Sweden. In a large population sample, 2 screening questions were used to identify individuals with pain once a week or more in the orofacial area. Incidence and longitudinal course of orofacial pain were evaluated using annual data for 2010 to 2017. To evaluate predictors for orofacial pain remaining over time, individuals who reported pain on at least 2 consecutive dental check-ups were considered persistent. A generalized estimating equation model was used to analyze the prevalence, accounting for repeated observations on the same individuals. In total, 180,308 individuals (equal gender distribution) were examined in 525,707 dental check-ups. More women than men reported orofacial pain (odds ratio 2.58, 95\% confidence interval [Cl] 2.48-2.68), and there was a significant increase in the prevalence of reported pain from 2010 to 2017 in both women and men. Longitudinal data for 135,800 individuals were available for incidence analysis. Women were at higher risk of both developing orofacial pain (incidence rate ratio $2.37 ; 95 \% \mathrm{Cl} 2.25-2.50$ ) and reporting pain in consecutive check-ups (incidence rate ratio 2.56; $95 \% \mathrm{Cl}$ 2.29-2.87). In the northern Swedish population studied, the prevalence of orofacial pain increases over time and more so in women, thus indicating increasing differences in gender for orofacial pain.
\end{abstract}

Keywords: Chronic pain, Facial pain, Gender, Orofacial pain, Temporomandibular disorders, Incidence, Prevalence

\section{Introduction}

Chronic pain is related to a broad range of interacting external and internal factors. The complex interplay between such factors determines the susceptibility for an individual to develop a chronic pain condition. The enigma of pain with regard to chronification and treatment resistance has led to the concept of "stickiness" being proposed, which incorporates how an event or perturbation may influence the development of chronicity in vulnerable individuals. ${ }^{5}$ For the individual, chronic pain often has a detrimental impact on the quality of life. ${ }^{8,42}$ Furthermore, chronic pain incurs substantial societal costs, especially in the context of the

\footnotetext{
Sponsorships or competing interests that may be relevant to content are disclosed at the end of this article.

a Department of Orofacial Pain and Jaw Function, Faculty of Odontology, Malmö University, Malmö, Sweden, ${ }^{b}$ Department of Odontology/Clinical Oral Physiology, Faculty of Medicine, University of Umeå , Umeå, Sweden, ' ${ }^{c}$ Section of Sustainable Health, Department of Public Health and Clinical Medicine, Umeå University, Umeå, Sweden, ${ }^{d}$ Department of Orofacial Pain and Dysfunction, Academic Centre for Dentistry Amsterdam (ACTA), University of Amsterdam and Vrije Universiteit, Amsterdam, the Netherlands, ${ }^{e}$ Centre for Oral Health Research, School of Dental Sciences, Newcastle University, Newcastle, United Kingdom

${ }^{*}$ Corresponding author. Address: Department of Clinical Oral Physiology, Faculty of Medicine, University of Umeå, Umeå 901 87, Sweden. Tel.: + 46703103214. E-mail address: anna.lovgren@umu.se (A. Lövgren).

PAIN 161 (2020) 1768-1775

Copyright (C) 2020 The Author(s). Published by Wolters Kluwer Health, Inc. on behalf of the International Association for the Study of Pain. This is an open-access article distributed under the terms of the Creative Commons Attribution-Non CommercialNo Derivatives License 4.0 (CCBY-NC-ND), where it is permissible to download and share the work provided it is properly cited. The work cannot be changed in any way or used commercially without permission from the journal.

http://dx.doi.org/10.1097/j.pain.0000000000001872
}

global burden of pain where pain related to the musculoskeletal system has been identified as a key element. ${ }^{4}$

Orofacial pain with a prevalence of $10 \%$ to $15 \%$ in the adult population $^{23,25}$ is one of the most common causes of chronic pain after back, neck, and knee pain., ${ }^{7,51}$ Acute pain in the orofacial area is often tooth related, ${ }^{24}$ whereas chronic orofacial pain is most commonly related to musculoskeletal disorders, temporomandibular disorders (TMDs). ${ }^{31}$ Temporomandibular disorder is the umbrella term embracing pain and dysfunction that involves the masticatory muscles, the temporomandibular joint, and associated structures. ${ }^{11,24}$ The economic burden on society from orofacial pain is substantial ${ }^{10}$; this stresses the importance of enhancing understanding of its natural course. The incidence and prevalence of TMD pain have been investigated in adults overall, ${ }^{12}$ adults aged 18 to $44,{ }^{44}$ and in adolescents. ${ }^{22}$ From early adolescence, the prevalence of orofacial pain increases and more so in girls, ${ }^{22,35}$ and it is twice as high in adult women compared with men. ${ }^{12,25}$ It was suggested that development of TMD pain in adolescence may reflect an underlying vulnerability for musculoskeletal pain. ${ }^{22}$

The biopsychosocial model, as a concept, is firmly embedded in the understanding and assessment of chronic pain. Thus, psychosocial factors have been shown to have a strong association with the development and persistence of orofacial pain ${ }^{13,44}$ and common comorbidities in chronic pain conditions. In light of reports of increasing prevalence of psychosocial factors such as stress, depression, and anxiety in the general population, especially in young adults and adolescents, ${ }^{46}$ it is reasonable to assume that this trend may also be reflected as an increase in the prevalence of orofacial pain. 
Early intervention is suggested to be important in patients with pain to prevent development of chronicity. ${ }^{30}$ Even so, a fluctuating pattern of orofacial pain related to TMD has been proposed, ${ }^{9,32}$ although there is currently a lack of knowledge with regard to individual susceptibility, the natural course of orofacial pain, and risk factors for chronification. Improved understanding of the natural course and predictors for chronic orofacial pain may not only offer targets for intervention and understanding of pathophysiological mechanisms, but also for development of strategies for personalized prevention and treatment. To shed light on why pain persists in some individuals and not in others, we also need to achieve a better understanding of the possible fluctuations of orofacial pain in the population.

The aim of this study was to analyze the incidence, prevalence, and chronification over time of orofacial pain related to TMD over an 8-year period in a large population sample.

\section{Materials and methods}

\subsection{Study setting}

The study was conducted at all Public Dental Health services (PDHS) in the county of Västerbotten, Sweden. In Sweden, dental care is provided by the PDHS and by private practitioners. Dental care is subsidized by the government, regardless of whether the patient chooses PDHS or private alternatives. In total, approximately $80 \%$ of the Swedish population undergo routine dental check-ups on a regular basis. ${ }^{14}$ Economic reasons are regarded as the main factor that causes individuals to refrain from dental care. Individuals who do not see a dentist regularly are mostly young, have low income, have low education, are on sick leave, and have bad health in general, including dental health. ${ }^{14}$ The county of Västerbotten consists of almost 270,000 inhabitants. ${ }^{45}$ Of these, $70 \%$ see their dentist on a regular basis and a majority undergo such routine dental check-ups at a PDH clinic. The demographics of this patient group are similar in terms of age and gender to the general population in the Västerbotten county. ${ }^{25}$

As part of the routine dental check-ups, individuals answered 3 screening questions for TMD (3Q/TMD) that are included in the mandatory part of the digital health questionnaire in the PDHS. The screening questions were added in May 2010 to the health declaration at all PDH clinics in Västerbotten ${ }^{25}$ to enable identification of individuals who could benefit from a further TMD examination. The screening questions are administered verbally from the examining dentist or dental hygienist as a part of the medical history at the regular dental check-ups. Because this is performed in a single appointment and before the clinical examination, no drop outs are expected. The screening questions have been introduced in large parts of Sweden to enable detection of individuals who could benefit from a further examination. In addition to identifying self-reported orofacial pain complaints, the questions were shown valid for the most common TMD-pain diagnoses. ${ }^{26,36}$ In this study, the first 2 questions on pain were used to identify individuals with orofacial pain. The questions are answered "yes" or "no" and are formulated as follows:

Q1: Do you have pain in your temple, face, jaw, or jaw joint once a week or more?

Q2: Do you have pain once a week or more when you open your mouth or chew?

Individuals with at least one affirmative answer were classified as orofacial pain cases.

The study was approved by the regional ethical board at Umeå University.

\subsection{Study population}

All individuals aged 5 or older who underwent a routine dental check-up from May 2010 to December 2017 were included.

\subsection{Exclusion criteria}

Individuals with a temporary personal identity number were excluded. In Sweden, all individuals receive a personal identity number at birth. Immigrants will receive a temporary personal identity number, normally for a period covering the first year of residency in Sweden. When a residence permit is granted, the temporary number is replaced with a permanent personal identity number. Individuals with a temporary personal identity number were excluded since they could not be followed over time.

\subsection{Incidence cohort}

For the incidence analysis, only individuals who did not report orofacial pain at their first check-up were included. Since the first check-up was used to filter out individuals entering the cohort with pain, contribution of person-years to the incidence cohort started at the second examination, that is, one per year in which a check-up took place until the last available check-up or until becoming a case. Incidence was calculated for 3 separate case definitions-onset of orofacial pain, recurrent orofacial pain, and persistent orofacial pain.

\subsection{Incidence of recurrent and persistent pain cohort}

The first criterion for both recurrent and persistent orofacial pain cases was that pain was reported on more than one examination. For recurrent cases, the second criterion was defined as individuals with at least one negative report between 2 positive reports. For persistent cases, the second criterion was that pain was reported in at least 2 consecutive routine check-ups within a 4-year period. In this incidence analysis, individuals with only one additional check-up were excluded because, by definition, they could not be categorized as recurrent or persistent pain cases.

\subsection{Statistical methods}

Descriptive statistics were used to characterize the study population. The 12-month prevalence of orofacial pain was calculated annually from 2010 to 2017 and was stratified on gender. Because all individuals with a regular dental check-up together with a completed digital health declaration were included, missing data were individuals who had additional routine dental check-ups but without a digital health declaration being completed at the same appointment. Therefore, missing data were expected to be low and not included in the analyses. Generalized estimating equation (GEE) models with logit function were used to analyze the prevalence, accounting for repeated observations of the same individuals in the data, stratified on gender. The model estimated the effect of gender, age, and each calendar year for the period 2010 to 2017 . From a previous study on the prevalence of the screening questions, ${ }^{25}$ we know that there is a nonlinear relationship between age and prevalence of orofacial pain. Therefore, the GEE model included natural cubic spline terms for evaluating the risk of developing orofacial pain over the life span, with 5 knots at the 16.7th, 33.3rd, 50th, 66.7th, and $83.3 r d$ percentiles of the age distribution. To further investigate and to statistically test for differences in age and 
calendar year effects between men and women, an additional GEE model was fitted that included a gender main effect and gender interactions effects with age and calendar year.

In the studied region, an education program on TMD for dentists and dental staff and information on how to use the screening questions were conducted during the autumn of 2013 and the spring of 2014 in 14 of the 33 clinics within the region. Since this could potentially influence the results, the year-wise analysis controlled for this factor.

We calculated the annual incidence rate in the study population as the ratio between the number of cases and the total number of person-years of the individuals at risk. Incidence rate ratios (IRRs) between women and men were estimated with Poisson regression, adjusted for age at first check-up using natural cubic splines with 3 knots at the 10th, 50th, and 90th percentile of the age distribution.

Considering the large sample size, and to decrease the risk of type I errors, a probability level $<0.01$ was regarded as statistically significant. All statistical analyses were conducted in $\mathrm{R}$ version 3.5.3. ${ }^{38}$ The GEE model was fitted using the geeg/m function from the geepack package. ${ }^{19}$ The STROBE checklist was followed. ${ }^{6}$

\section{Results}

In total, 180,308 unique individuals, with an equal distribution of men and women (50.0\%), were examined in 525,707 routine dental check-ups from 2010 to 2017 (Fig. 1). The mean age at the first examination was 34.3 (SD 22.7) years with each individual having a median number of 3 examinations over the 8 -year period (Table 1). The screening questions were answered in $87 \%$ of the dental check-ups over the years (Table 2).

The prevalence of frequent orofacial pain was significantly higher in women compared with men (OR 2.58, 95\% confidence interval [Cl] 2.48-2.68). There was a significant increase in the prevalence of orofacial pain for both women and men over the 8year period (Table 2 and Fig. 2). The prevalence of orofacial pain was calculated by age and gender in 37,647 individuals and adjusted at calendar year 2010 (Fig. 3). The highest prevalence

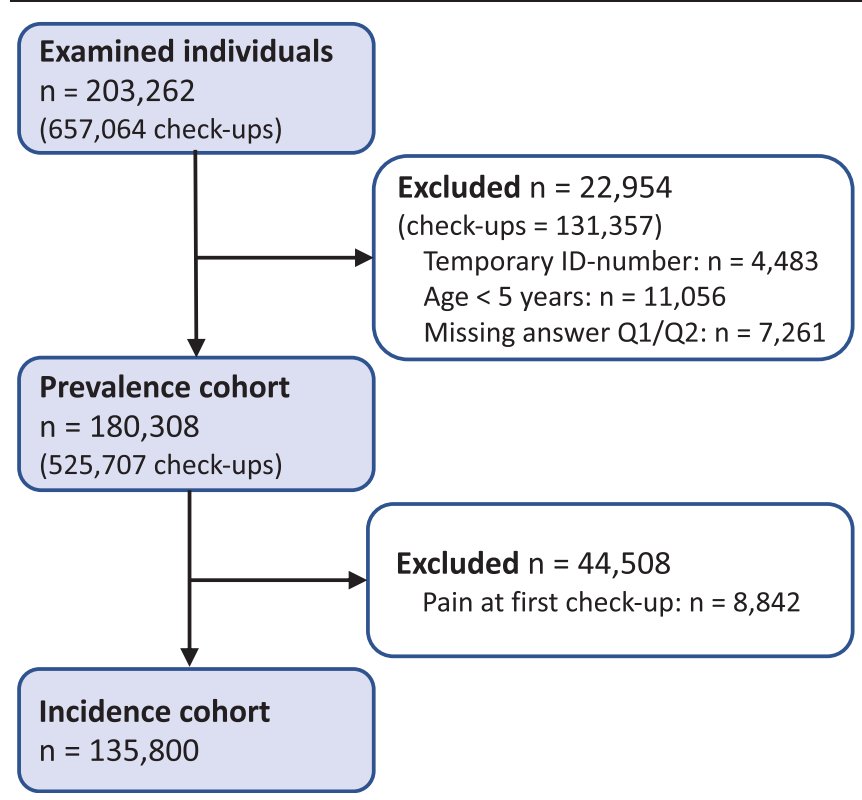

Figure 1. Flowchart of the study population. Excluded participants may be present in more than one of the subgroups. was found in adult women (20-70 years of age). This pattern was consistent across the calendar years (Fig. 4).

The increase in prevalence from 2010 to 2017 was primarily caused by an increase in affirmative answers to the question of pain in the orofacial region (Q1). This increase in prevalence of orofacial pain was first found from 2013 to $2014(P<0.001)$ with the highest increase primarily among adult women $(P=0.058)$ (Fig. 5).

In total, 135,800 pain-free individuals were included in the incidence analysis (Table 1). There were 6594 individuals (4.9\%) with incidence pain. The annual incidence rate of onset of orofacial pain related to TMD was $2.5 \%$ in women and $1.2 \%$ in men, with women at a higher risk compared with men (IRR 2.37; 95\% Cl 2.25-2.50) (Table 3). In total, 2734 individuals (2.7\%) were categorized as recurrent pain, of which 1434 (1.4\%) were categorized as persistent cases (Table 3). Therefore, among those who reported first onset pain, 22\% developed persistent pain. For persistent pain, the annual incidence rate was $0.7 \%$ in women and $0.3 \%$ in men. Women were at a higher risk of developing persistent orofacial pain compared with men (IRR 2.56; 95\% Cl 2.28-2.87), (Table 3). Among those who developed persistent pain, 210 individuals (14.6\%) later reported pain remission at some point.

\section{Discussion}

The main finding from this large prospective population study was an unexpected increase in the prevalence of orofacial pain over the study period. Although the magnitude was larger for women, the increase was due to both genders reporting more pain over time. The overall age pattern remained similar over the 8-year period. Among the individuals who developed persistent pain, only a minority recovered.

In the Swedish dental system, patients are routinely examined annually or biannually based on individual risk assessment. Because our data are based on information from those dental check-ups, annual data are not available for all individuals in the studied 8-year period. To obtain a study sample of this size, it was not possible to perform clinical examinations, and instead, 2 screening questions were used to identify individuals with orofacial pain. These questions were shown to be valid and suitable for screening purposes and have been evaluated both for adolescents and adults in relation to a TMD pain diagnosis, ${ }^{26,36}$ which is the most common chronic orofacial pain condition. ${ }^{24}$

The screening questions have therefore been introduced in large parts of the health care system in Sweden to identify individuals with orofacial pain. Because the questions concern pain in the orofacial area, as well as pain on jaw function, they may also identify individuals with non-TMD pain such as neuropathic or odontogenic pain. In 9\% of individuals, affirmative answers to the screening questions were related to dental pain. ${ }^{27}$

However, the screening questions have been evaluated for criterion validity in relation to the diagnostic criteria for TMD, DC/ TMD. In a subsample of the current study population, affirmative answers to any of the 2 questions were primarily associated with a TMD pain diagnosis with a sensitivity of 0.82 and specificity of $0.87,{ }^{26}$ whereas among patients referred to a specialist clinic due to pain complaints, the sensitivity and specificity were 0.96 and 0.33 , respectively. ${ }^{28}$ Given that the subjective nature of pain justifies self-reported assessment, these screening questions could be a suitable measure for orofacial pain complaint, often related to the most common chronic orofacial pain condition, TMD. ${ }^{24}$ 
Table 1

Demographical characteristics of the total study sample examined May 2010 to December 2017 in Västerbotten county, Sweden, and the number of examinations for each individual over the 8-year period for the whole sample $(n=180,308)$, for the subsample included in the incidence analysis* $(n=135,800)$ and among individuals with recurrent or persistent pain, respectively.

\begin{tabular}{|c|c|c|c|c|c|c|c|c|c|c|c|}
\hline & \multirow{2}{*}{$\frac{\text { Sample }}{\mathrm{n}}$} & \multicolumn{2}{|l|}{ Age } & \multicolumn{8}{|c|}{ No. of examinations for each individual, $n$ (\%) } \\
\hline & & $\begin{array}{l}\text { Mean } \\
\text { (SD) }\end{array}$ & Median (IQR) & 1 & 2 & 3 & 4 & 5 & 6 & 7 & 8 \\
\hline Total & 180,308 & $34.3(22.7)$ & $29.0(16.0-29.0)$ & $38,026(21.1)$ & $35,794(19.9)$ & $42,724(23.7)$ & $38,518(21.4)$ & $18,921(10.5)$ & $5165(2.9)$ & $1041(0.6)$ & $119(0.1)$ \\
\hline Women & 90,166 & $34.9(23.0)$ & $30.0(15.0-30.0)$ & $19,071(21.2)$ & $18,015(20.0)$ & $21,392(23.7)$ & $19,196(21.3)$ & $9347(10.4)$ & $2539(2.8)$ & $540(0.6)$ & $66(0.1)$ \\
\hline Men & 90,142 & $33.7(22.4)$ & $29.0(15.0-29.0)$ & $18,955(21.0)$ & $17,779(19.7)$ & $21,332(23.7)$ & $19,322(21.4)$ & $9574(10.6)$ & $2626(2.9)$ & $501(0.6)$ & $53(0.1)$ \\
\hline \multicolumn{12}{|l|}{$\begin{array}{l}\text { Incidence } \\
\text { cohort }\end{array}$} \\
\hline Total & 135,800 & $33.0(22.6)$ & $28.0(14.0-28.0)$ & $\mathrm{N} / \mathrm{A}$ & $33,987(25.0)$ & $40,780(30.0)$ & $36,805(27.1)$ & $18,153(13.4)$ & $2389(3.6)$ & $995(0.7)$ & $115(0.1)$ \\
\hline Women & 66,509 & $33.5(23.0)$ & $28.0(14.0-28.0)$ & $\mathrm{N} / \mathrm{A}$ & $16,755(25.2)$ & $20,008(30.1)$ & $17,984(27.0)$ & 8804 (13.2) & $2389(3.6)$ & $506(0.8)$ & $63(0.1)$ \\
\hline Men & 62,291 & 32.5 (22.3) & $27.0(14.0-27.0)$ & $\mathrm{N} / \mathrm{A}$ & $17,232(24.9)$ & $20,772(30.0)$ & $18,821(27.2)$ & $93,49(13.5)$ & $2576(3.7)$ & $489(0.7)$ & $52(0.1)$ \\
\hline \multicolumn{12}{|l|}{$\begin{array}{l}\text { Recurrent/ } \\
\text { persistent } \\
\text { cohort }\end{array}$} \\
\hline Total & 101,813 & $32.3(22.5)$ & $26.0(13.0-26.0)$ & $\mathrm{N} / \mathrm{A}$ & $\mathrm{N} / \mathrm{A}$ & $40,780(40.1)$ & $36,805(36.1)$ & $18,153(17.8)$ & $4965(4.9)$ & $995(1.0)$ & $115(0.1)$ \\
\hline Women & 49,754 & 32.7 (22.9) & $27.0(13.0-27.0)$ & $\mathrm{N} / \mathrm{A}$ & N/A & 20,008 (40.2) & $17,984(36.1)$ & 8804 (17.7) & $2389(4.8)$ & $506(1.0)$ & $63(0.1)$ \\
\hline Men & 52,059 & $31.9(22.1)$ & $26.0(13.0-26.0)$ & $\mathrm{N} / \mathrm{A}$ & $\mathrm{N} / \mathrm{A}$ & 20,772 (39.9) & 18,821 (36.2) & $9349(18.0)$ & $2576(4.9)$ & $489(0.9)$ & $52(0.1)$ \\
\hline
\end{tabular}

To the best of our knowledge, this is the largest sample followed over an extended period with regard to orofacial pain. The study sample covers more than half of the population of the county of Västerbotten with an equal distribution of men and women as well as comparable ages for the county on the whole. ${ }^{25}$ Low education and poor general health are examples of sociodemographic factors related to orofacial pain and to not seeing a dentist regularly. ${ }^{16,34}$ Since our sample was based on regular dental attendees, selection bias may cause an underestimation of prevalence. However, missing data were generally low as individuals answered mandatory questions on verbal instruction from the dental care provider. Thus, taken together, this study provides both robust data and real-life evidence from a large sample over a sufficient period to evaluate incidence, prevalence, and persistence of orofacial pain in the population. $^{3}$

In this study, the overall age pattern of the prevalence of orofacial pain over the life span, with a higher prevalence in middle-aged adults, complies with previous reports on musculoskeletal pain, eg, back pain. ${ }^{2,7}$ We also found a twin peak pattern of prevalence for orofacial pain, which is in accordance with previous reports on smaller samples. For example, a twin peak age pattern of prevalence was reported in a study based on a sample of 383 individuals that indicated 2 major age-clustered groups of TMD patients. ${ }^{17,51}$ We confirm this twin peak pattern at baseline in 2010 for 37,647 individuals, and this pattern was especially distinct in adult women. The similarity in the pattern of prevalence of orofacial pain achieved by our screening questions compared with a full clinical examination ${ }^{17}$ is in itself noteworthy. This can be interpreted as a confirmation of the validity of the screening questions in relation to a TMD-pain diagnosis and is in line with previous reports on the prevalence of TMD. ${ }^{26,36}$ Furthermore, the study design we used allowed for a novel and reliable comparison of this overall age pattern of prevalence of orofacial pain over an 8-year period and revealed that this pattern remained consistent over the examined calendar years.

In the HUNT study, 3405 individuals were examined annually over a 4-year period by a questionnaire that included 2 questions on pain. From the results, it was suggested that both development and recovery from pain was highly dependent on previous pain. ${ }^{20}$ Of the individuals who reported first onset of pain, 38\% reported pain also the following year. This is higher

Table 2

The 1-year period prevalence of orofacial pain with $95 \% \mathrm{Cl}$ for the full study period, stratified on sex.

\begin{tabular}{|c|c|c|c|c|c|c|c|}
\hline \multirow[t]{2}{*}{ Year } & \multirow[t]{2}{*}{ Coverage (\%) } & \multicolumn{3}{|l|}{ Women } & \multicolumn{3}{|l|}{ Men } \\
\hline & & $\bar{n}$ & Cases & Prevalence (95\% Cl) & $\bar{n}$ & Cases & Prevalence $(95 \% \mathrm{Cl})$ \\
\hline 2010 & 51.7 & 18,659 & 1456 & $7.8(7.4-8.2)$ & 18,988 & 610 & $3.2(3.0-3.5)$ \\
\hline 2011 & 88.8 & 34,058 & 2329 & $6.8(6.6-7.1)$ & 34,505 & 946 & $2.7(2.6-2.9)$ \\
\hline 2012 & 89.3 & 32,183 & 2280 & $7.1(6.8-7.4)$ & 32,568 & 970 & $3.0(2.8-3.2)$ \\
\hline 2013 & 90.3 & 33,050 & 2355 & $7.1(6.8-7.4)$ & 33,131 & 932 & $2.8(2.6-3.0)$ \\
\hline 2014 & 92.6 & 33,504 & 2599 & $7.8(7.5-8.0)$ & 33,545 & 1163 & $3.5(3.3-3.7)$ \\
\hline 2015 & 93.9 & 38,426 & 3237 & $8.4(8.1-8.7)$ & 38,400 & 1261 & $3.3(3.1-3.5)$ \\
\hline 2016 & 95.0 & 37,307 & 3192 & $8.6(8.3-8.8)$ & 37,294 & 1373 & $3.7(3.5-3.9)$ \\
\hline 2017 & 95.0 & 35,159 & 3238 & $9.2(8.9-9.5)$ & 34,930 & 1320 & $3.8(3.6-4.0)$ \\
\hline
\end{tabular}

The proportion of screened individuals at regular dental check-ups at each year is given as percentage of data coverage.

$\mathrm{Cl}$, confidence interval. 

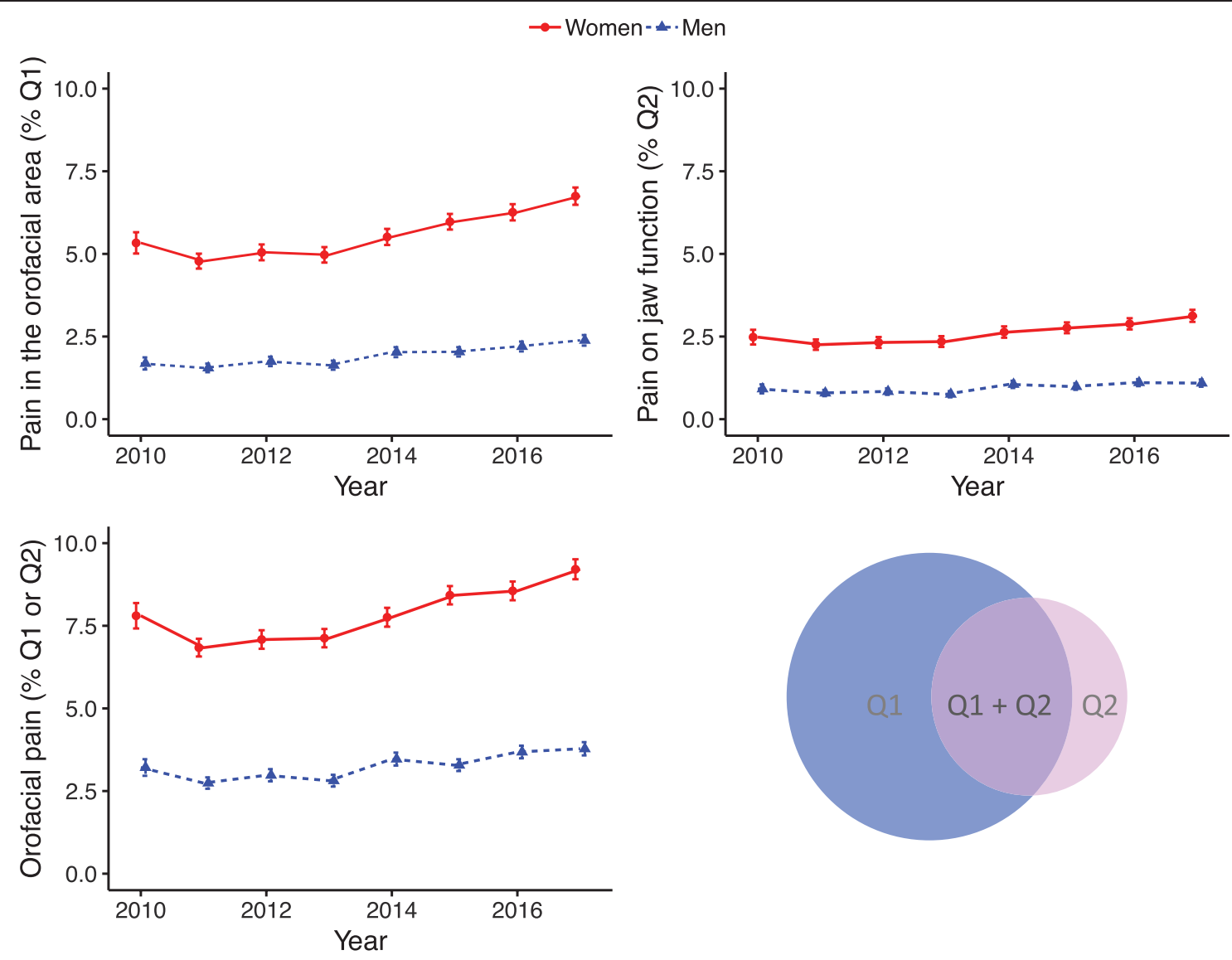

Figure 2. The prevalence in women and men with affirmative answers to $2 \mathrm{Q} / \mathrm{TMD}$ from 2010 to 2017 ( $n=187,487)$ together with a Venn diagram showing the overlap between the 2 questions on orofacial pain.

than our results where $22 \%$ of individuals with onset of orofacial pain reported pain also at the consecutive check-up. These proportions were also confirmed in a longitudinal follow-up of clinical diagnoses over 5 years. Among the individuals who had myofascial pain at baseline, 31\% continued to have a disorder over the studied period. ${ }^{40}$ Taken together, this demonstrates an overall pattern of persistence of orofacial pain, similar to bodily

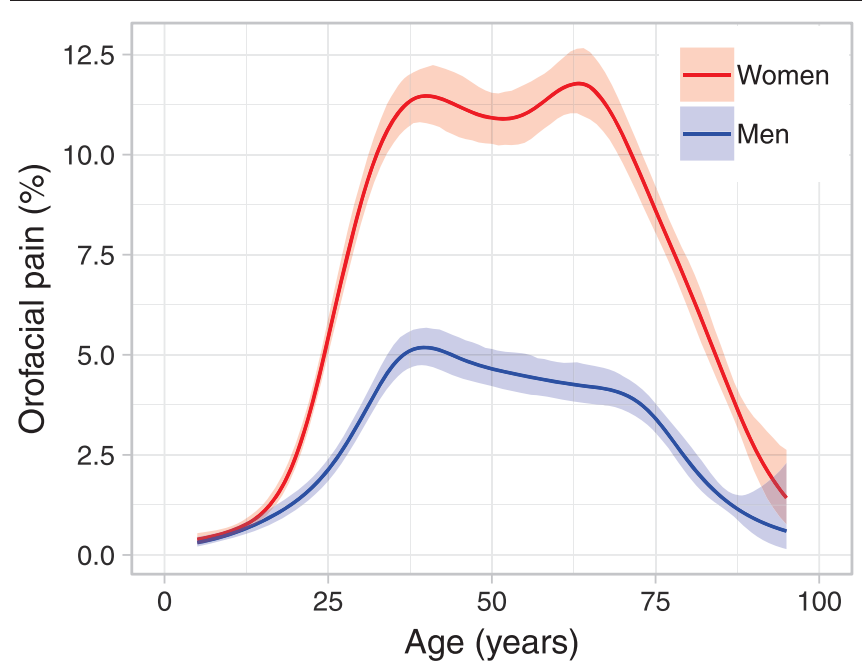

Figure 3. The estimated prevalence of orofacial pain as a function of age, adjusted at year $2010(n=37,647)$. pain on the whole, and that approximately 1 out of 5 individuals who develop orofacial pain will develop a long-term pain condition.

In further analysis of the HUNT cohort, it was concluded that pain intensity was related to the degree of chronification. ${ }^{21}$ Pain intensity was also identified as a risk factor for the transition from acute into a chronic orofacial pain condition ${ }^{15}$ as well as for the persistence of pain. ${ }^{33}$ Pain intensity does not, however, always predict disability. In a previous study using the same screening questions as in this study, we showed that $55 \%$ of individuals from the general population who screened positive and qualified for a TMD diagnosis reported a moderate pain intensity or functional limitations. ${ }^{26}$ However, how pain intensity and disability are related to the development of pain and in relation to affirmative answers to the screening questions in this study is yet to be established.

Despite the consistent age pattern of prevalence, we demonstrate a significant increase in the prevalence of orofacial pain in the second part of the 8-year period. This was mainly caused by the increasing prevalence of reported orofacial pain in women. This gender difference was also present in the incidence analysis. Although female gender is related to a higher prevalence due to long-lasting symptoms, ${ }^{29}$ gender as a specific risk factor for first-onset TMD pain is debated. ${ }^{1,43}$ The prospective OPPERA cohort study reported a higher incidence of $3.9 \%$ but with only marginally greater incidence in women, ${ }^{43}$ whereas our results show that women were more than twice as likely as men to develop orofacial pain as well as persistent pain. This gender difference, commencing and progressing from early adolescence, is however 


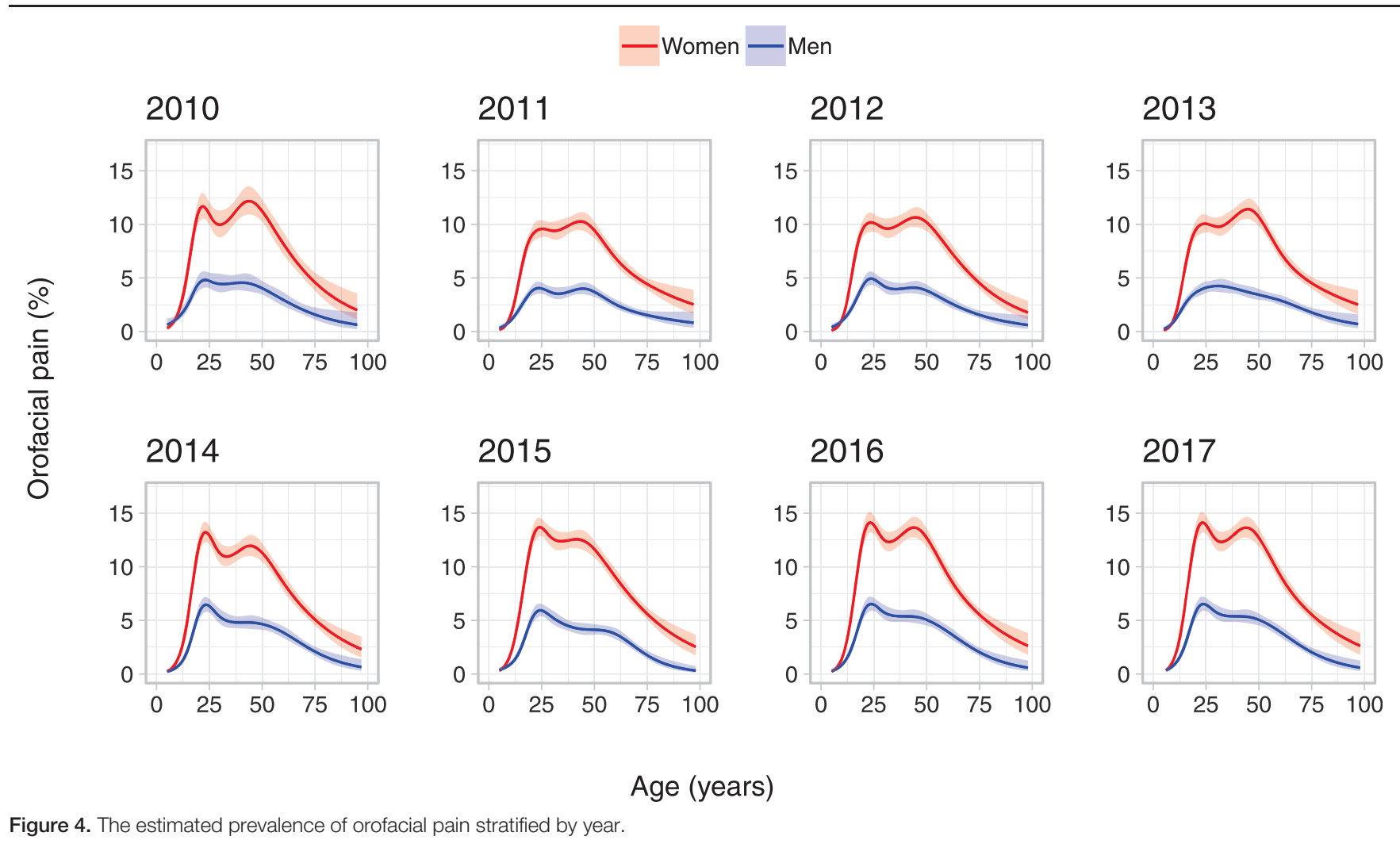

in line with previous studies in adolescents. ${ }^{22,35}$ Possible factors behind these gender differences could include genetic factors affecting pain vulnerability as well as hormonal and psychosocial factors. ${ }^{48,50}$ Given the importance of the biopsychosocial model in relation to the development of chronic pain, the overall increase in orofacial pain found in this study might be related to a myriad of interacting factors. Psychological conditions such as anxiety and stress are on the rise in the population, especially in young adults, ${ }^{46}$ and psychological factors have previously been identified as contributing to both incidence ${ }^{43}$ and persistence ${ }^{37}$ of orofacial pain. Thus, catastrophizing, and especially rumination, has been reported to be associated with pain intensity, pain persistence, and pain disability in patients with TMD. ${ }^{41,47}$ Chronic pain is also related to suicide. ${ }^{39}$ Again, this highlights the importance of assessment of psychosocial factors ${ }^{39}$ and adds further support for psychosocial screening also in primary dental care, ${ }^{18,49}$ which will also aid in assessing the prognosis for a positive treatment outcome. ${ }^{37}$

Our findings point to several directions for future research. Individual-specific risk factors, not only for the risk of first onset of orofacial pain but also in the transition from acute into chronic pain, should be further evaluated on a population basis. This is especially so since the traits for chronic pain conditions may be present already at first onset of pain. Among the possible risk factors suggested, biomarkers including metabolomics and genetic factors may be present and warrant further investigations.

Taken together, our findings indicate that in addition to the already established gender difference in the prevalence of pain, including orofacial pain, this difference between men and women is on the rise. In addition, and in contrast to previous reports on
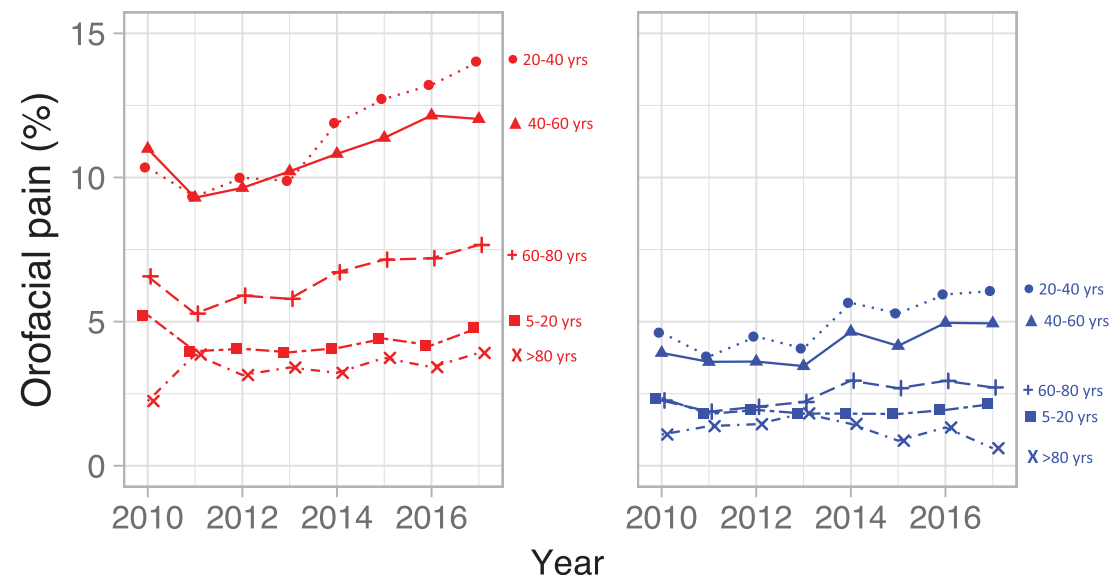

Year

Figure 5. The prevalence of orofacial pain from 2010 to 2017 for women (red) and men (blue) for the different age groups. 
Table 3

Incidence and risk of developing orofacial pain for the incidence cohort $(n=135,800)$ and for the recurrent/persistence cohort ( $n=101,813)$.

\begin{tabular}{|c|c|c|c|}
\hline Sex & Cases, n (\%) & Annual incidence (\%) & Incidence rate ratio $(95 \% \mathrm{Cl})$ \\
\hline \multicolumn{4}{|c|}{ Incidence pain* $(n=135,800)$} \\
\hline Total & $6594(4.9)$ & & \\
\hline Women & $4541(6.8)$ & 2.49 & $2.37(2.25-2.50)$ \\
\hline Men & $2053(2.9)$ & 1.22 & 1.0 \\
\hline \multicolumn{4}{|c|}{ Incidence recurrent pain† ( $n=101,813)$} \\
\hline Total & $2734(2.7)$ & & \\
\hline Women & $1932(3.9)$ & 1.35 & $2.58(2.38-2.80)$ \\
\hline Men & $802(1.6)$ & 0.53 & 1.0 \\
\hline \multicolumn{4}{|c|}{ Incidence persistent pain $\ddagger(n=101,813)$} \\
\hline Total & $1434(1.4)$ & & \\
\hline Women & $1012(2.0)$ & 0.70 & $2.56(2.28-2.87)$ \\
\hline Men & $422(0.8)$ & 0.28 & 1.0 \\
\hline
\end{tabular}

* Orofacial pain $\geq 1$ check-up.

† Orofacial pain $\geq 2$ check-ups.

$\ddagger$ Orofacial pain $\geq 2$ consecutive check-ups.

fluctuating symptoms of TMD pain over time, ${ }^{9,32}$ persistent orofacial pain was as frequent as fluctuations. Furthermore, our results indicate that most individuals who develop a persistent orofacial pain condition will not recover.

In conclusion, this study found a consistent age pattern but increasing prevalence of orofacial pain, mainly caused by an increase of orofacial pain in women. The present results indicate that in terms of "stickiness" of pain, ${ }^{5}$ women are more at risk. The findings show that the prevalence of orofacial pain in our northern Swedish population is increasing over time and more so in women, indicating an increasing gender difference for persistent orofacial pain.

\section{Conflict of interest statement}

The authors have no conflicts of interest to declare.

\section{Acknowledgements}

Financial support was provided through regional agreement between Umeå University and Västerbotten County Council on cooperation in the field of Medicine, Odontology and Health.

\section{Article history:}

Received 2 September 2019

Received in revised form 12 January 2020

Accepted 12 March 2020

Available online 16 March 2020

\section{References}

[1] Bair E, Ohrbach R, Fillingim RB, Greenspan JD, Dubner R, Diatchenko L, Helgeson E, Knott C, Maixner W, Slade GD. Multivariable modeling of phenotypic risk factors for first-onset TMD: the OPPERA prospective cohort study. J Pain 2013;14(12 suppl):T102-115.

[2] Bardel A, Wallander MA, Wedel H, Svardsudd K. Age-specific symptom prevalence in women 35-64 years old: a population-based study. BMC Public Health 2009;9:37.

[3] Bellows BK, Kuo KL, Biltaji E, Singhal M, Jiao T, Cheng Y, McAdam-Marx C. Real-world evidence in pain research: a review of data sources. J Pain Palliat Care Pharmacother 2014;28:294-304.

[4] Blyth FM, Huckel Schneider C. Global burden of pain and global pain policycreating a purposeful body of evidence. PAIN 2018;159(suppl 1):S43-8.

[5] Borsook D, Youssef AM, Simons L, Elman I, Eccleston C. When pain gets stuck: the evolution of pain chronification and treatment resistance. PAIN 2018;159:2421-36.
[6] Brand RA. Standards of reporting: the CONSORT, QUORUM, and STROBE guidelines. Clin Orthop Relat Res 2009;467:1393-4.

[7] Breivik H, Collett B, Ventafridda V, Cohen R, Gallacher D. Survey of chronic pain in Europe: prevalence, impact on daily life, and treatment. Eur J Pain 2006;10:287-333.

[8] Dahlstrom L, Carlsson GE. Temporomandibular disorders and oral health-related quality of life. A systematic review. Acta Odontol Scand 2010;68:80-5.

[9] de Leeuw R, Klasser GD. Differential diagnosis and management of TMDs. In: de Leeuw R, Klasser GD, editors. Orofacial pain: guidelines for assessment, diagnosis, and management. Hanover Park: Quintessence Publishing Co, Inc, 2018. pp. 143-207.

[10] Durham J, Shen J, Breckons M, Steele JG, Araujo-Soares V, Exley C, Vale L. Healthcare cost and impact of persistent orofacial pain: the DEEP study cohort. J Dent Res 2016;95:1147-54.

[11] Dworkin SF, LeResche L. Research diagnostic criteria for temporomandibular disorders: review, criteria, examinations and specifications, critique. J Craniomandib Disord 1992;6:301-55.

[12] Dworkin SF, Huggins KH, LeResche L, Von Korff M, Howard J, Truelove E, Sommers E. Epidemiology of signs and symptoms in temporomandibular disorders: clinical signs in cases and controls. J Am Dent Assoc 1990;120:273-81.

[13] Fillingim RB, Slade GD, Greenspan JD, Dubner R, Maixner W, Bair E, Ohrbach R. Long-term changes in biopsychosocial characteristics related to temporomandibular disorder: findings from the OPPERA study. PAIN 2018;159:2403-13.

[14] Försäkringskassan. Swedish Social Insurance Agency (Försäkringskassan). https://www.forsakringskassan.se/wps/wcm/connect/4183aaa3-bad6-4f7dac7d-c315d56c657e/socialforsakringsrapport_2012-10.pdf?MOD=AJPERES. Accessed 9 January 2020.

[15] Garofalo JP, Gatchel RJ, Wesley AL, Ellis E III. Predicting chronicity in acute temporomandibular joint disorders using the research diagnostic criteria. J Am Dent Assoc 1998;129:438-47.

[16] Gillborg S, Akerman S, Lundegren N, Ekberg EC. Temporomandibular disorder pain and related factors in an adult population: a cross-sectional study in southern Sweden. J Oral Facial Pain Headache 2017;31:37-45.

[17] Guarda-Nardini L, Piccotti F, Mogno G, Favero L, Manfredini D. Agerelated differences in temporomandibular disorder diagnoses. Cranio 2012;30:103-9.

[18] Häggman-Henrikson B, Ekberg E, Ettlin DA, Michelotti A, Durham J, Goulet JP, Visscher CM, Raphael KG. Mind the gap: a systematic review of implementation of screening for psychological comorbidity in dental and dental hygiene education. J Dent Educ 2018;82:1065-76.

[19] Halekoh U, Højsgaard S, Yan Jun. The R package geepack for generalized estimating equations. J Stat Softw 2006;15:1-11.

[20] Landmark T, Dale O, Romundstad P, Woodhouse A, Kaasa S, Borchgrevink PC. Development and course of chronic pain over 4 years in the general population: the HUNT pain study. Eur J Pain 2018;22: 1606-16.

[21] Landmark T, Romundstad P, Butler S, Kaasa S, Borchgrevink P. Development and course of chronic widespread pain: the role of time and pain characteristics (the HUNT pain study). PAIN 2019;160:1976-81. 
[22] LeResche L, Mancl LA, Drangsholt MT, Huang G, Von Korff M. Predictors of onset of facial pain and temporomandibular disorders in early adolescence. PAIN 2007;129:269-78.

[23] LeResche L. Epidemiology of temporomandibular disorders: implications for the investigation of etiologic factors. Crit Rev Oral Biol Med 1997;8:291-305.

[24] Lipton JA, Ship JA, Larach-Robinson D. Estimated prevalence and distribution of reported orofacial pain in the United States. J Am Dent Assoc 1993;124:115-21.

[25] Lövgren A, Häggman-Henrikson B, Visscher CM, Lobbezoo F, Marklund S, Wänman A. Temporomandibular pain and jaw dysfunction at different ages covering the lifespan — a population based study. Eur J Pain 2016;20:532-40.

[26] Lövgren A, Visscher CM, Häggman-Henrikson B, Lobbezoo F, Marklund $S$, Wänman $A$. Validity of three screening questions $(3 \mathrm{Q} / \mathrm{TMD})$ in relation to the DC/TMD. J Oral Rehabil 2016;43:729-36.

[27] Lövgren A, Marklund S, Visscher CM, Lobbezoo F, Häggman-Henrikson B, Wänman A. Outcome of three screening questions for temporomandibular disorders (3Q/TMD) on clinical decision-making. J Oral Rehabil 2017;44:573-9.

[28] Lövgren A, Parvaneh H, Lobbezoo F, Häggman-Henrikson B, Wänman A, Visscher CM. Diagnostic accuracy of three screening questions (3Q/ $\mathrm{TMD}$ ) in relation to the $\mathrm{DC} / \mathrm{TMD}$ in a specialized orofacial pain clinic. Acta Odontol Scand 2018;76:380-6.

[29] Macfarlane TV, Blinkhorn AS, Davies RM, Kincey J, Worthington HV. Predictors of outcome for orofacial pain in the general population: a fouryear follow-up study. J Dent Res 2004;83:712-17.

[30] Macfarlane GJ. The epidemiology of chronic pain. PAIN 2016;157: 2158-9.

[31] Maixner W, Diatchenko L, Dubner R, Fillingim RB, Greenspan JD, Knott C, Ohrbach R, Weir B, Slade GD. Orofacial pain prospective evaluation and risk assessment study - the OPPERA study. J Pain 2011;12(11 suppl):T4-11.e11-12.

[32] Manfredini D, Guarda-Nardini LG. TMD classification and epidemiology. In: Manfredini D, editor. Current concepts on temporomandibular disorders. New Malden: Quintessence Publishing Co. Ltd, 2010. pp. 25-39.

[33] Meloto CB, Slade GD, Lichtenwalter RN, Bair E, Rathnayaka N, Diatchenko L, Greenspan JD, Maixner W, Fillingim RB, Ohrbach R. Clinical predictors of persistent temporomandibular disorder in people with first-onset temporomandibular disorder: a prospective case-control study. J Am Dent Assoc 2019;150:572-81.e510.

[34] Mills SEE, Nicolson KP, Smith BH. Chronic pain: a review of its epidemiology and associated factors in population-based studies. $\mathrm{Br} \mathrm{J}$ Anaesth 2019;123:e273-83.

[35] Nilsson IM, List T, Drangsholt M. Prevalence of temporomandibular pain and subsequent dental treatment in Swedish adolescents. J Orofac Pain 2005; 19:144-50.

[36] Nilsson IM, List T, Drangsholt M. The reliability and validity of self-reported temporomandibular disorder pain in adolescents. J Orofac Pain 2006;20: 138-44.

[37] Penlington C, Araujo-Soares V, Durham J. Predicting persistent orofacial pain: the role of illness perceptions, anxiety, and depression. JDR Clin Trans Res 2019;5:40-9.
[38] R: A language and environment for statistical computing. Vienna: R Foundation for Statistical Computing, 2019.

[39] Racine M. Chronic pain and suicide risk: a comprehensive review. Prog Neuropsychopharmacol Biol Psychiatry 2018;87(pt B):269-80.

[40] Rammelsberg P, LeResche L, Dworkin S, Mancl L. Longitudinal outcome of temporomandibular disorders: a 5-year epidemiologic study of muscle disorders defined by research diagnostic criteria for temporomandibular disorders. J Orofac Pain 2003;17:9-20.

[41] Reiter S, Eli I, Mahameed M, Emodi-Perlman A, Friedman-Rubin P, Reiter MA, Winocur E. Pain catastrophizing and pain persistence in temporomandibular disorder patients. J Oral Facial Pain Headache 2018;32:309-20.

[42] Shueb SS, Nixdorf DR, John MT, Alonso BF, Durham J. What is the impact of acute and chronic orofacial pain on quality of life? J Dent 2015; 43:1203-10.

[43] Slade GD, Bair E, Greenspan JD, Dubner R, Fillingim RB, Diatchenko L, Maixner W, Knott C, Ohrbach R. Signs and symptoms of first-onset TMD and sociodemographic predictors of its development: the OPPERA prospective cohort study. J Pain 2013;14(12 suppl):T20-32 e21-23.

[44] Slade GD, Ohrbach R, Greenspan JD, Fillingim RB, Bair E, Sanders AE, Dubner R, Diatchenko L, Meloto CB, Smith S, Maixner W. Painful temporomandibular disorder: decade of discovery from OPPERA studies. J Dent Res 2016;95:1084-92.

[45] Statistics Sweden. Available at: https://www.scb.se/en/finding-statistics/ statistics-by-subject-area/population/population-composition/populationstatistics/pong/tables-and-graphs/yearly-statistics-municipalitiescounties-and-the-whole-country/population-in-the-country-counties-andmunicipalities-on-31-december-2019-and-population-change-in-2019/. Accessed September 1, 2019.

[46] Twenge JM, Cooper AB, Joiner TE, Duffy ME, Binau SG. Age, period, and cohort trends in mood disorder indicators and suicide-related outcomes in a nationally representative dataset, 2005-2017. J Abnorm Psychol 2019;128:185-99.

[47] Velly AM, Look JO, Carlson C, Lenton PA, Kang W, Holcroft CA, Fricton JR. The effect of catastrophizing and depression on chronic pain-a prospective cohort study of temporomandibular muscle and joint pain disorders. PAIN 2011;152:2377-83.

[48] Visscher CM, Lobbezoo F. TMD pain is partly heritable. A systematic review of family studies and genetic association studies. J Oral Rehabil 2015;42:386-99.

[49] Visscher CM, Baad-Hansen L, Durham J, Goulet JP, Michelotti A, Roldan Barraza C, Haggman-Henrikson B, Ekberg E, Raphael KG. Benefits of implementing pain-related disability and psychological assessment in dental practice for patients with temporomandibular pain and other oral health conditions. J Am Dent Assoc 2018;149:422-31.

[50] Visscher CM, Schouten MJ, Ligthart L, van Houtem CM, de Jongh A, Boomsma DI. Shared genetics of temporomandibular disorder pain and neck pain: results of a twin study. J Oral Facial Pain Headache 2018;32: 107-12.

[51] Von Korff M, Dworkin SF, Le Resche L, Kruger A. An epidemiologic comparison of pain complaints. PAIN 1988;32:173-83. 